subjective sensation of insecurity has grown considerably in recent years, including in cities that can be counted as among the safest in the world. Within Latin America, Briceño-León identifies Argentina as one of the region's least violence-prone countries (Table 2), yet recent media discourses in that country could lead one to imagine that a war without quarter is raging between society and violent criminals, and private security provision has become one of the country's few growth industries. If we accept the proposition that discourse can impact on behavior, I believe it is a logical second step to integrate a critical analysis of discourse into this explanatory model as a factor that foments violence.

On a more general level, and from a West European perspective, the question arises: What is the role of the state in all this? The notable weakness of the Latin American state, especially in its legal dimension (as argued above all by Guillermo O'Donnell) has a huge impact on citizenship, and the state fails in its most fundamental and essential task, that of guaranteeing a basic level of physical security for its citizens. Thus, weak state performance is reflected not only in an inability to fulfill welfare functions, but also in non-fulfillment of the central function of providing security. Given this, it is perhaps not surprising that life in many of Latin America's cities is "solitary, poor, nasty, brutish, and short", just as Hobbes imagined life before the social contract. Of course there are exceptions within the region, states such as Chile and Costa Rica, where the state is comparatively strong in its legal dimension and the level of interpersonal violence is low (lower indeed than in an old-established democracy like the United States, as Briceño-León points out), as well as important gradations that should make us cautious about sweeping generalities. In one respect, the situation is worse than Hobbes' imagined state of nature, for not only does the state fail to provide a minimum level of security, but it also invests its agents with an authoritative power that is frequently used arbitrarily and with no regard for legality. Citizens are thus doubly insecure, threatened by high levels of interpersonal violence and also by state agents whose supposed function is to protect them. Pre-state forms of political organization no longer exist, and the state, through its agents, is effectively an additional source of violence through its acts of omission and commission. This argument does not (necessarily) imply the need for more security agents, but rather points to the need for more rule of law. The weakness of the state in its legal dimension

is also directly relevant to the meaning of citizenship. If we define citizenship with Tilly ${ }^{1}$ ( $\mathrm{p}$. 253) as " a set of mutually enforceable claims relating categories of persons to agencies of government", we can readily perceive that the concept has little meaning where formal claims, foremost among them the right to a basic level of physical security, are effectively non-enforceable. The ideal of urbanity thus gives way to the truncated citizenship described by Briceño-León.

1. Tilly C. Conclusion: why worry about citizenship? In: Hanagan M, Tilly C, editors. Extending citizenship, reconfiguring states. Lanham: Rowman \& Littlefield; 1999. p. 247-59.

\title{
The author replies
}

El autor replica

Roberto BriceñoLeón
I wish to begin by expressing my appreciation for the generous comments and sharp criticism sparked by my article. The opportunity offered by the Debates section of Cadernos de Saúde Pública confirms the key importance that the scientific community ascribes to expanding our knowledge and scientific practice. It behooves me to humbly and joyfully accept such comments and criticism, because the precise remarks on the aspects that are missing or that merit greater substantiation reveal our limitations. The commentary is valid and demonstrates our inevitably limited way of reconstructing the world, and the intelligent and knowledgeable debate is so varied culturally and professionally that it allows me to move forward and improve the sociological framework through which I propose to understand violence, refining its favorable aspects and correcting its flaws.

At the end of a beautiful text on the empirical basis of knowledge, Popper 1 proposes a metaphor according to which we do not build our knowledge on a rock, but rather on muddy ground. That epistemological premise always holds true, because a theory's role is to blaze 
trails; it does not pretend to cover everything, but rather some essential aspects; it does not propose to eliminate complexity, but to make it somewhat more comprehensible and manageable for researchers and policy-makers.

I will answer the comments and criticisms with the purpose of intensifying and continuing the debate, not to close it or to treat it as concluded.

\section{The definition of violence and homicides}

Several commentators have insisted on the definition of violence I used and why the term is restricted to homicides when there are many other expressions of violence.

We at LACSO use a simple but restricted definition of violence that has a strong operational value: "the use or credible threat of use of physical force against others or oneself” 2 (p. 196). This definition is very similar to those used by the WHO in its World Report on Violence and Health 3 , the National Research Council of the National Academy of Sciences 4, and the American Sociological Association 5, but we prefer to limit our definition to physical violence (we do not consider psychological or structural forms or their consequences, which may be physical or psychological). We do not distinguish whether the act is committed against an individual or a social group, or if it results from legal action (capital punishment in some countries) or illegal. Some definitions associate violence with any serious offense: speaking in a loud voice and with a certain tone, using offensive language in an argument, or even using silence as an instrument can entail major psychological aggression. We see a basis to this and agree with Bandura 6 that this type of behavioral response is intended to harm others, and is thus similar to violence; however, we think it is inadequate to place insult and homicide on the same level of harm. Therefore, like Bandura, we prefer to call all such offenses aggression, but use violence exclusively for acts with a physical component and the use of force.

Still, physical aggression varies widely, from slapping one's spouse in the face to passionate homicide, from a fistfight at school to a shootout between gangs. Our studies consider all these forms of violence 7,8 , but I have limited myself to its most dramatic and irreversible form: homicide. There are several reasons for this choice. The statistics are much more reliable for mortality than violence rates in general. We can reasonably trust the figures on consummat- ed homicides, unlike those on failed attempts, where victims are only injured. Statistics on overall violence are not highly reliable because crimes are rarely reported in Latin America, since victims and their relatives fear reprisal by aggressors and have little trust in the police to offer effective protection (or in the criminal justice system to punish the perpetrators). Filing complaints is thus risky and has little benefit, and this has a negative impact on statistics.

We also intend to show an important change in the criminal perspective: the new violence is striking not so much because of the increase in crime as a whole, but because of the increase in violent crime and its lethalness. This was described in the United States in a landmark study 9 , but a similar trend has occurred in Latin America. In the 1950s and 60s, in the golden era of capitalist growth, juvenile gangs fought with knives and chains, while they now wield high-powered weapons. The social conflict is the same, but the lethalness of firearms is different, and homicides are thus a relevant indicator of the new violence. The current violence also gives us a different perspective from that of criminology, considering the phenomenon not from an individual perspective, but from a social one, as so-called critical criminology has done 10 . Individual motives are not important to us, nor are serial killers or those with an individual pathology. The social fact of violence is important because of its magnitude. Most killers in Latin America are not mentally ill, but ordinary young people with the drama of a senseless life devoid of a future, in which they describe with astonishing tranquility and with no remorse how they have killed two, three, or more people. In their restricted social milieu, violence has become normal in the Durkheimian sense 11, and they are only actors of that normality.

\section{The city and crime}

The history of cities is linked to state control of violence and the constitution of individual rights. Of course cities have not been a haven for saints. I do not see the city as paradise. Rather, I attempt to retrieve the notion of citizenship connected to the city as a privileged place for individual rights.

Early theoreticians of urban sociology like Robert Ezra Park 12 viewed the city as the place where natural instincts were controlled and the cultural order was constructed. In a metaphor with categories from the second topic of Freud, the city is the place where the Uber-Ich (super- 
ego) takes precedence over the rebel $E s$ (id) 13, or in more contemporary terms, where social control based on the rule of law is imposed.

In a rural society controlled by landowners and their private armies, with a limited institutional base or state power, the cities represented the place where rights could be pursued. In rural society, order was based on customs and the traditional social division of power. There might be tranquility, but with no individual rights or rule of law. In Latin America, the city represented a place to which peasants could migrate in search of welfare and freedom. If it is difficult today to organize rural unions or peasants' movements, we can only imagine the situation in the 1930s and 40s, when people had less schooling and there was no mass media to report abuses. I have not meant to say that people left the countryside because of insecurity or violence, but because they were searching for the welfare and rights offered by urban capitalist society. I do not claim that cities were a paradise, but that despite their deficiencies and difficulties, they offered better conditions than the abandonment people experienced in the countryside. Interestingly, in Colombia some 2 to 3 million displaced persons have fled to the cities, terrified by the rural guerrilla warfare. Although violence in Colombian cities is extremely serious, people feel they have some protection. In the insecurity of the city, they can aspire to more security. They can enjoy something of the citizenship that is denied to them in the countryside.

Cities represented modernity, with rights and benefits and the possibility of a normative order and opportunities. That dynamic is found in studies on urbanization 14 . The $20^{\text {th }}$ century Latin American city does not correspond to the urban industrial model of Europe or the United States. Rather, it resembles the pre-capitalist city that was the seat of the landowners who spent the rural surplus there. However, the magnitude of the phenomenon far exceeded the city's possibilities, and that is what I argue, that the phenomenon was rapid and widespread and raised hopes that were eventually frustrated. This does not involve the question of whether cities are producers of violence. Quite to the contrary, they tended to reduce violence, as occurred with the first generation to arrive in the cities. However, when many more migrants arrived and the process became overwhelming, a new generation was born and the city became a hostile environment where one had to resort to violence to survive.

Minayo's data on Brazil clearly show that the problem is shifting from the countryside to the urban areas and from small towns to large cities, and that urbanization in Latin America tends to concentrate power, wealth, and violence.

My analysis on violence and the city acknowledges the influence I have received from the Chicago school of urban sociology (also called human ecology) 15 . Contemporary sociology has neglected how the population's spatial location and distribution influences people's behavior and societal organization, one of the great lessons from studies by Burgués \& Lucke 16 on the family and how this changed according to the concentric zones they identified in American cities, or the analysis by Bell 17 on the relationship between behavior by the mafia in the Port of New York and the possibilities arising from intricate territorial organization of the docks. My proposed model reclaims the importance of situational analysis, both in its strictly physical dimension of the city and areas, and in the social and political conditions that actors identify as possibilities for their course of violent action.

\section{The specificity of violence in Latin America}

Violence is becoming increasingly homogeneous worldwide, but two different processes occur in parallel. First, the mechanisms of violence are increasingly similar because the operational modes of violence and crime have spread, and delinquents learn and repeat them in different countries and regions. Second, there are local specificities whereby these mechanisms are adapted to the circumstances in each city or country.

This occurs as a consequence of the globalization that makes societies and possibilities for crime more similar. For example, the widespread use of ATMs offers an opportunity for crime. Criminals first attempted to break the machines to remove the cash, but they soon realized it was easier to threaten card holders at gunpoint and force them to withdraw the money. Thus was how the so-called "flash kidnappings" spread so quickly around the world, as fast as ATMs have been installed. Violence has also gone global as a cultural process. Perhaps the most relevant example is that of the "maras", or Central American youth gangs, stemming from cultural exchange through the merger between gangs from Los Angeles and the dynamics of poor youth in El Salvador. Thus the term " mara salvatrucha" ( mara = group; salva = El Salvador; trucha = friends). The phenomenon spread to other neighboring countries and oth- 
er cities in the United States and Spain, in places where Central American migrants have reached, reproducing an apparently local phenomenon elsewhere.

But violence is not identical worldwide. WHO statistics show an important difference between regions in the proportion of suicides and homicides (Table 12). In Africa and the Americas there are two or three times more homicides than suicides, while the opposite occurs in Europe and the Western Pacific.

Africa and Latin America are not completely similar. The figures for Latin America are far higher, because the rate shown in Table 12 for the Americas includes the WHO classification with the United States and Canada, so that the Latin America rates are really higher than shown, surpassing those of Africa. The African situation is also different because it includes a component of war that does not exist in Latin America. The violence in South Africa is probably most similar to that of Latin America, possibly because as a nation it is also more similar to the Latin American countries.

Despite Africa's great poverty, its inequality has been historically lower than in Latin America, although these differences tended to decrease in the 1990s. Milonevic 18 explains this situation based on a hypothesis by Kutznets, whereby African countries are characterized by agriculture and widespread poverty, and in such cases the differences between lower and higher income strata tend to be smaller. Table 13 shows the Gini coefficients and per capita GDP for three regions, where Latin America has the greatest inequality.

\section{The relationship between poverty and violence}

A topic that has received great interest and criticism is shown in Table 6, where I report on

Table 12

Homicide and suicide rates by regions of the World Health Organization (per 100,000 inhabitants).

\begin{tabular}{lcc}
\hline Regions, WHO & Homicides & Suicides \\
\hline Africa & 22 & 7 \\
America & 19 & 8 \\
Europe & 8 & 19 \\
Western Pacific & 4 & 21 \\
\hline
\end{tabular}

Source: based on data from WHO 3 poverty, urbanization, and homicides. The commentators' observations and suggestions are appropriate, and these data certainly require more detailed analysis and better presentation.

The idea was to identify an important research path through aggregate data showing differences between countries and suggesting that in countries with high urbanization and high poverty there are more homicides than in others with only one of these conditions. The purpose was to formulate a hypothesis in this direction. Based on this and the very limitations of a text (already quite long) that attempted to touch on multiple dimensions rather than delving deeply into any of them, we did not perform the statistical tests that the discussants are fairly requesting.

However, I do wish to clear up a possible misunderstanding. I do not believe that poverty is a direct cause of violence. When there is high urbanization and high poverty what really exists is extensive social inequality, yet the most urbanized areas of Latin America are also those with the greatest wealth. We agree (and have written) that poverty itself is not a cause of violence, but the majority of both victims and perpetrators are poor. The worst violence is not in Haiti, Northeast Brazil, or the poorest areas of Venezuela or Mexico. It occurs where there has been heavy, rapid urbanization and poverty coexisting with wealth, as in São Paulo, Rio de Janeiro, Caracas, and Mexico City. My hypothesis takes this direction.

\section{The cultural dynamic and violence}

Violence is a cultural act in its origins and consequences. I thus agree that we should pay more attention to the hedonistic culture and consumerism that dominates the aspirations of citizens and is converted into frustration and a motive for violence. But it is interesting that these processes occur under circumstances in which it is not possible to seize the wealth from others. A study by Nisbett \& Cohen 19 on the culture of honor argues that this distinguishes the violence in agricultural as compared to pastoral economies, because in the latter it is possible to seize wealth (cattle) more easily than robbing crops. In a culture of consumerism, objects form part of the individual's "being", so to kill or be killed for a pair of shoes means a struggle for the essence, for identity, and violence is the means that allows conquering the objects that permit one to be a person. We thus argue that violence gives sense to some senseless lives. 
Few studies approach violence from a gender perspective, which should really be considered in a much broader dimension. Most studies on violence and gender focus on violence against women. We did not want to emphasize the importance of the culture of masculinity as a factor in the gender dimension of social relations and ways to solve conflicts, and we thus limited it to a factor that foments violence. However, we agree that this issue must be extended to other factors, because for example the meaning of weapons as phallic symbols is relevant to the construction of masculinity, in children's games, and in power management among men.

The role of the mass media (especially television) in violence is a true challenge for the social sciences. Managing this issue is very difficult, since it covers highly diverse topics. We believe it is necessary to avoid excesses such as classifying pornography on television as violence 20. However, it is relevant for violent movies, where the hero decapitates dozens of people in a few seconds, and violent cartoons like Tom and Jerry. The issue also relates to the treatment of news and to what extent it responds to the legitimate right of citizens to be informed or to scandalize them and to take delight in violence for marketing purposes. The effects are highly diverse, and the importance delinquents assign to the media and their pride in saving and flaunting newspaper clippings showing them in photographs is surprising. They display not shame, but pride in being recognized as someone on the "social pages" of crime.

Much further research is needed on such effects and on a theoretical matrix that imposes limits but respects individual rights and freedom. The media serve as a powerful weapon, and as with all power regulations, a counterbalance must be imposed on them. Still, the easy resort to censorship and control must be avoided as highly risky in societies with such a fragile institutional base and with authoritarian temptations such as those existing in Latin America. The question posed by Norberto Bobbio thus acquires great force: who controls the controllers?

\section{Rule of law and the state}

In Latin America the government may be weak or strong, but the state is always weak. There is a fragile institutional base that is able to pass many laws, but is unable to enforce norms or punish violators. The discussants are right when
Table 13

Inequality in three different regions, 1998.

\begin{tabular}{lccc}
\hline & Africa & Latin America & Asia \\
\hline Mean Gini & 47.1 & 50.5 & 35.6 \\
Gini standard deviation & 7.9 & 6.2 & 7.7 \\
Average GDP per capita & 1,670 & 5,825 & 6,177 \\
\hline
\end{tabular}

Source: based on Milonevic 18.

they say that this aspect is not fully developed in the paper and should be part of the sociological framework I propose.

The lack of a strong institutional base (a solid state and the rule of law) contributes to the increase in violence, both by inducing delinquency through impunity and propitiating violent responses by citizens (attempts at social cleansing, etc.), who feel unprotected, and by the police, who justify their extrajudicial action on the grounds that they must apply direct punishment since the criminal justice system fails to do so.

This same institutional weakness fuels a sense of insecurity among citizens, who feel they receive inadequate protection from the state (or in some cases even worse, that state agencies pose a threat). The resulting dynamic is highly complex. In many cities the police force has been cleaned up to expel or punish delinquent members, and while citizens applaud such measures, their fears are confirmed, namely that the border is fuzzy between police and criminal violence.

Just as the standard of living is subjective, so is security. Security is a subjective sensation based on both experience (personal or vicarious) and information obtained about reality. In the development of this sensation, people's expectation of security in the social context plays a key role: in safer cities, even minor violence is portrayed as serious by the media, while in others a dramatic event is necessary to impress the public. Thus, disarmament campaigns in some countries have used drawings with crossedout revolvers, while in Colombia mothers have painted silhouettes of sub-machine guns on their posters protesting against violence.

This dynamic of reality and perception of state policies and society has its effects. I am unfamiliar with the situation in São Paulo, but according to some analysts the decrease in homicides in Brazil is related to the program to restrict possession of firearms and limitations on alcohol consumption (Diadema). In Colom- 
bia, Bogotá and Cali have taken to measures against the factors that facilitate violence, and public policies have been implemented to restrict alcohol consumption on certain dates to limit possession of guns. Meanwhile, in Cali a youth employment program was developed that would not affect the macro social processes of unemployment that we describe as an originating factor, but which could have an impact on the final expression and provide opportunities for many youths. Some poor areas now have multi-purpose public buildings with combined services (police, care for battered women, primary health care) demonstrating the state's presence close to the people. Campaigns have been conducted in Bogotá to motivate and promote peaceful conflict resolution and civic behavior (including clowns as animators), while changing people's perception of the state and helping improve the city's life and economy. This is surprising in a country with high levels of conflict and violence, but this may also be where people have felt the greatest impact of violence and have decided they need to seek alternatives.

\section{References}

1. Popper K. La lógica de la investigación científica. Madrid: Tecnos; 1962.

2. Briceño-León R, Camardiel A, Avila O, Armas E, Zubillaga V. La cultura emergente de la violencia en Caracas. Revista Venezolana de Economía y Ciencias Sociales 1997; 3:195-214.

3. World Health Organization. World report on violence and health. Geneva: World Health Organization; 2002.

4. Reiss A, Roth J. Understanding and preventing violence. Washington DC: National Academies Press; 1993.

5. Levine F, Rosich K. Social causes of violence: crafting a science agenda. Washington DC: American Sociological Association; 1995.

6. Bandura A. Aggression: a social learning theory. Englewood: Prentice-Hall; 1973.

7. Briceño-León R, Camardiel A, Avila O, Armas E. La violencia doméstica: predoctores sociales y culturales. Acta Científica Venezolana 1998; 49: 248-59.

8. Zubillaga V, Briceño-León R. Exclusión, masculinidad y respeto: algunas claves para entender la violencia entre adolescentes en barrios. Nueva Sociedad 2001; 173:34-78.

9. Zimring FE, Hawkins G. Crime is not the problem. Lethal violence in America. New York: Oxford University Press; 1977.

10. Del Olmo R. América Latina y su criminología. México DF: Siglo XXI; 1981.

\section{Our infinite ignorance}

I have left many questions unanswered. Neither my abilities nor the common sense that prevents us from abusing the space provided by this fine journal would allow otherwise. But that is how science is, making advances by correcting our errors. Violence is multidimensional, and my contribution to the debate is not intended to be exhaustive. Rather, it is proposed as a theoretical framework allowing us to place some order in the myriad of variables and factors, making them more comprehensible and orienting future research to identify the real scope of public policies, depending on the types of factors which may become targets for intervention.

Our knowledge is neither definitive nor useless. Our disagreement keeps the desire to search alive and our doubts serve as a stimulus, all of which confirms the beautiful expression by Popper 21 (p. 29): “Our knowledge can only be finite, while our ignorance must necessarily be infinite."
11. Durkheim E. Les règles de la méthode sociologique. Paris: Presses Universitaires de France; 1999.

12. Park RE. Human communities: the city and human ecology. Glencoe: The Free Press; 1952.

13. Freud S. El yo y el ello. Obras completas, v. III. Madrid: Biblioteca Nueva; 1973.

14. Germani G. Sociología de la modernización. Buenos Aires: Paidós; 1971.

15. Briceño-León R. La naturalización de lo social. In: Acosta M, Briceño-León R, editors. Ciudad y capitalismo. Caracas: Ediciones de la Biblioteca de la Universidad Central; 1987. p. 79-96.

16. Burgués E, Lucke F. The family: from institution to companionship. New York: American Book Company; 1953.

17. Bell D. El fin de las ideologías. Madrid: Tecnos; 1964.

18. Milonevic B. Is inequality in Africa really different? Washington DC: World Bank; 2003.

19. Nisbett RE, Cohen D. Culture of honor: the psychology of violence in the South. Oxford: Westview Press; 1996.

20. Kriegel B. La violence á la televisión. Rapport de la misión d'evaluation, d'analyse et de propositions relatives aux représentations violentes á la televisión. Paris: Presses Universitaires de France; 2003.

21. Popper K. Conjectures and refutations. The growth of scientific knowledge. London: Routlegdge/ Kegan Paul; 1972. 